\begin{tabular}{|c|c|c|}
\hline $\begin{array}{l}\text { PKS } \\
\text { PUBLIC } \\
\text { KNOWEDGE } \\
\text { PROJECT }\end{array}$ & $\begin{array}{c}\text { REVISTA DE GEOGRAFIA } \\
\text { (RECIFE) } \\
\text { http://www.revista.ufpe.br/revistageografia }\end{array}$ & $\begin{array}{l}\text { OJS } \\
\frac{\text { OPEN }}{\text { OPUNAL }} \\
\text { SYSTEMS }\end{array}$ \\
\hline
\end{tabular}

\title{
DIVERSAS PERSPECTIVAS INVESTIGATIVAS EN ECOLOGÍA POLÍTICA ${ }^{1}$
}

\author{
Mariana Elkisch ${ }^{1}$ \\ ${ }^{1}$ Professora da Universidad Autônoma da Cidade do México. Email: mariana.elkisch@uacm.edu.mx

\begin{abstract}
RESUMEN
El artículo discute procesos fundamentales vividos en nuestro tiempo. Enfatiza la agudización de los mecanismos de acumulación desplazados hacia el campo de la explotación de los recursos biológicos-naturales. Examina de manera analítica los argumentos y datos de la que apuntan en la tendencia actual de la intensificación de la naturaleza y de la vida a escala global.
\end{abstract} \\ Palabras clave: Ecología Política, mercantilización de la naturaleza, mercado de tierras, geografía económica.
}

\section{DIVERSAS PERSPECTIVAS NA PESQUISA EM ECOLOGIA POLÍTICA}

\section{RESUMO}

$\mathrm{O}$ artigo discute processos fundamentais vividos no nosso tempo. Enfatiza a agudização dos mecanismos de acumulação deslocados para o campo da exploração dos recursos biológicos-naturais. Examina de maneira analítica os argumentos e dados da que apontam na tendência atual da intensificação da natureza e da vida em escala global.

Palavras-chave: Ecologia Política, mercantilização da natureza, mercado de terras, geografia econômica.

\section{INTRODUCCIÓN}

Hace unos días una estudiante de la UACM escribía en su trabajo final: "me he dado cuenta que el capitalismo no se destruye, sólo se transforma". Creo que tiene razón. Y no mal entiendan lo que estoy diciendo, pues estoy convencida que es posible derrotar al capitalismo, pero hay que derrotarlo, él no morirá por sus propias contradicciones.

La historia del capitalismo es la historia del despojo violento. Esta narrativa, de alcances seculares, no es, sin embargo, una secuencia lineal. Debido a la voracidad propia del

\footnotetext{
${ }^{1}$ Este artigo é parte das reflexões realizadas durante o Seminario Latinoamericano de Ecología Política: saberes ambientais em defesa da vida. Realizado nos dias 17 e 18 de maio de 2017 na Universidad Autônoma da Cidade do México.
} 
capitalismo, la narrativa se va complejizando y va tejiendo, cada tanto, una nueva o renovada historia. Es decir, como advertía la estudiante uacemita, efectivamente el capitalismo se transforma.

El crecimiento económico bajo el capitalismo, nos decía Marx, es un proceso de contradicciones internas. El crecimiento armonioso y equilibrado bajo este modo de producción es puramente accidental siendo, por el contrario, la tendencia inevitable y recurrente hacia la crisis su característica endémica.

A partir de la década de los setenta el capitalismo, a escala del sistema en su conjunto, comenzó a experimentar una permanente dinámica de sobreacumulación que se tradujo, entre otros, en una estrepitosa caída de las tasas de ganancia. Así, el principal motor de la reorganización capitalista operada a partir de la década de los años setenta y que hoy conocemos como Neoliberalismo, ha sido, precisamente, la creación de condiciones para una acumulación renovada.

Dirigidos a implementar un nuevo modelo de acumulación capaz de recuperar la tasa de ganancia, una parte esencial del nuevo ciclo de acumulación se ha anclado en la ampliación de la escala de apropiación de trabajo ajeno. La desvalorización de la fuerza de trabajo y la flexibilidad laboral son dos estrategias combinadas que se han seguido para aumentar la explotación comprimiendo salarios reales, desmontando contratos colectivos, prolongando el ciclo de vida laboral y eliminando derechos fundamentales (salario mínimo, limitación legal de la jornada laboral, derechos de pensión y jubilación, reglamentación del trabajo femenino, prohibición del trabajo infantil). Esta embestida contra el trabajo está acompañada de la destrucción de las redes protectoras contenidas en las instituciones estatales de seguridad social (salud, educación, vivienda, seguro de desempleo), así como de los pactos corporativos en que se sostuvo la regulación estatal de las relaciones laborales durante el siglo $\mathrm{XX}$.

Ahora bien, además de profundizar la explotación del trabajo, hoy día gran parte de los mecanismos de acumulación se ha trasladado hacia la explotación de los recursos biológiconaturales y su incorporación a los circuitos de intercambio mercantil privado. Es decir, si la primera generación de privatizaciones neoliberales se enfocó sobre los activos del Estado y los servicios, actualmente se orienta de manera particular sobre los recursos naturales.

El despliegue de este intenso proceso de mercantilización global de los recursos naturales se ha traducido en la consolidación regional de un modelo de desarrollo basado en el 
impulso a proyectos extractivos (de amplio espectro) orientados, fundamentalmente, a la exportación. Así, desde el conservador gobierno de Santos en Colombia o Peña en México, hasta el "progresismo" uruguayo de Pepe Mújica o Evo Morales en Bolivia, la agenda extractivista se ha instalado en todos los países de América Latina.

Ciertamente para nuestros pueblos y territorios existe una memoria larga del extractivismo que se remonta a la conquista y colonización ibérica. Ahora bien, retrotrayendo la memoria de las más brutales centurias antecesoras, el actual modelo extractivo exportador, sea en su versión clásica o en su versión progresista, no puede considerarse como un simple ciclo de restauración del pasado extractivista. Es decir, si bien la lógica extractivista actual invoca y replica muchos de estos procesos, hoy día adopta nuevas o renovadas formas cuya novedad, y voracidad, se explican, en gran medida, a partir de tres grandes ejes: 1) las nuevas tecnologías y 2) la escasez, procesos que abordaré de manera general y 3) el capital financiero-especulativo.

\section{NUEVAS TECNOLOGÍAS Y ESCASEZ}

A partir de la década de los setenta del siglo XX somos testigos de un intenso desarrollo tecnológico organizado en torno a las tecnologías de la información. Este desarrollo científico y tecnológico, ha detonado el desarrollo a gran escala de cuatro grandes ejes de punta: a) la electroinformática/robótica; b) la ingeniería genétical biotecnología; c) la generación de nuevas energías, y d) la exploración de nuevos materiales.

Además de revolucionar el mundo de las comunicaciones transformando la geografía productiva y comercial, y de permitir la incorporación de tecnologías que revolucionan el ámbito de la producción humana y amplían la escala de apropiación privada del trabajo colectivo (Gilly y Roux, 2008), a partir de este patrón tecnológico se está desplegando un extenso y profundo proceso de mercantilización de la naturaleza y la vida a una escala global antes inimaginable (Seoane, 2012). Es decir, a partir de estas nuevas tecnologías, una amplia gama de recursos naturales "ya conocidos" están siendo resignificados o reconvertidos dentro del proceso de la industria tecnológica, al tiempo que otros que, hasta hace unas décadas, no se consideraban objeto de extracción de valor, ahora son incorporados al proceso de reproducción de capital. Es decir, hoy el desarrollo tecnológico permite la privatización de recursos naturales que antes o bien no requería el capital, o bien no había encontrado la forma de extraer, por ejemplo, el llamado Shale gas, o la información genética de las especies. 
A este proceso se suma otro elemento de re-valorización de los recursos biológiconaturales: el aumento en la escasez de recursos naturales no renovables. Tal es el caso del agua y el petróleo.

En este sentido, a partir del actual grado de desarrollo del patrón científico tecnológico y por el incremento en la escasez, nos enfrentamos a la configuración de una nueva o renovada relación entre el capital y los recursos biológico-naturales.

Esta renovada relación, se ha traducido en la reconfiguración no sólo del valor, sino de la ubicación espacial de las zonas altamente valiosas. Es decir, hoy los lugares que albergan los recursos biológico naturales se han convertido en lugares estratégicos para el capital y, por ende, en el centro de la disputa.Y vale la pena advertir que cuatro quintas partes de los recursos biológico-naturales se localizan en los territorios rurales del tercer mundo (Delgado, 2002: 63).

Las transformaciones que se derivan de esta suerte de re-valorización de los recursos naturales son muchas y no nos da esta intervención para abordarlas. Pero baste decir que bajo los referentes del capitalismo global estamos presenciando la configuración de otro tipo de ordenamiento territorial que se ajuste a la nueva reorganización productiva que se generó en el actual periodo científico-técnico e informacional. Y no estamos simplemente hablando de reacomodamientos en los territorios "modernizados" del centro y la periferia. Principalmente nos referimos a la funcionalización de los territorios rurales de la periferia que hasta ahora habían estado escasa o parcialmente articulados a los grandes ciclos del capital mundial (Cfr: Gómez Cárdenas y Puello-Socarrás 2009: 25).

Ahora bien, como señalamos hace un momento, la actual explotación de los recursos naturales ha adoptado nuevas formas. Su complejidad y perversidad tampoco nos dan para analizarlas en este espacio, sin embargo, permítanme ponerles algunos ejemplos de cómo opera esta nueva o renovada dinámica de explotación de los recursos naturales, en este caso vinculadas al capital financiero-especulativo

\section{ESPECULACIÓN FINANCIERA}

Como señalamos en párrafos anteriores, luego de la larga onda expansiva de la posguerra, a partir de la década de los setenta el capitalismo experimentó una permanente dinámica de sobreacumulación misma que se tradujo en una estrepitosa caída de las tasas de ganancia. Frente a la crisis de rentabilidad del capital productivo se instrumentaron una serie 
de reformas dirigidas, precisamente, a recuperar la tasa de ganancia. Una de las medidas centrales se ubicó en la desvalorización de la fuerza de trabajo. Ahora bien, aunque la imposición de bajos salarios y el fraccionamiento de los procesos industriales, relocalizados en la periferia, permitieron la obtención de cuotas elevadas de explotación, esta medida se topó con la estrechez del mercado y con ello graves problemas de realización. Por lo anterior, al tiempo que se promovió un profundo endeudamiento entre la población dirigido a generar capacidad de compra, paralelamente se fortaleció el desvío de una parte esencial del capital hacia la esfera financiera y especulativa.

A partir de que el capital financiero, pero sobre todo el especulativo, sometió a su lógica de funcionamiento a los sectores productivos extrayendo valor sin reinvertirlo productivamente, se comenzó a generar una masa dineraria sin representación de valor. Dicha situación provocó, entre otros, un proceso de sobreacumulación financiera cuya burbuja explotó de manera estrepitosa en el año 2007 en el sector inmobiliario, donde el capital se enfrentó al inmenso obstáculo que comporta el carácter fijo de un capital no realizado

Directamente relacionado con la desregulación financiera operada a inicios del siglo XXI, en el marco de la crisis en el ámbito inmobiliario, los precios del petróleo comenzaron a registrar un movimiento sostenido al alza lo cual, derivado del carácter petrodependiente de la agricultura industrial, se tradujo también en un incremento en el precio de los alimentos y de las materias primas en general.

\section{Lámina 1:}

Como se observa en la Gráfica 1, luego de la tendencia a la baja registrada a partir de la década de los setenta del siglo XX, en el año 2000 el precio de los alimentos comenzó a mostrar una tendencia sostenida al alza.

Gráfica 1. Comportamiento del precio de los alimentos(1900-2010) 


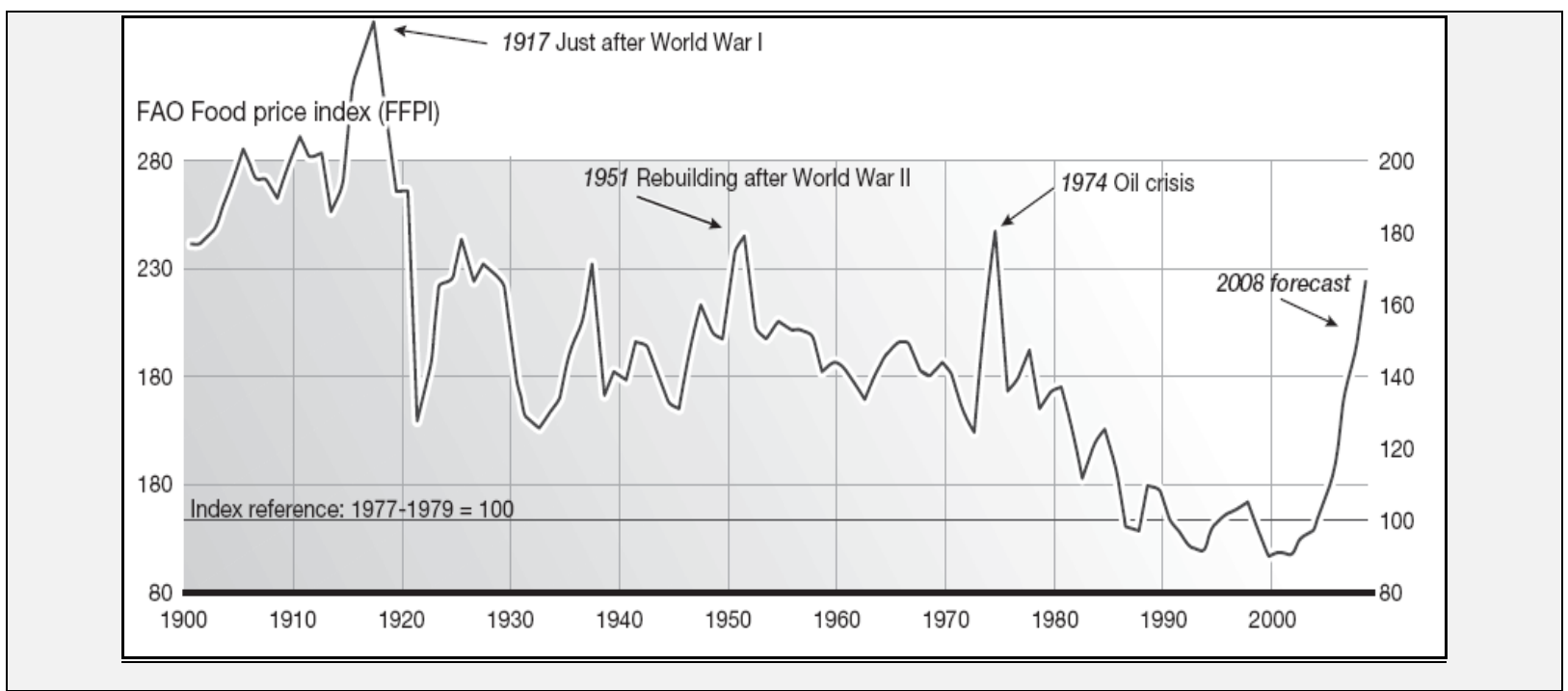

En el contexto de la crisis inmobiliaria, y favorecidos por la aplicación del amplio paquete de medidas desregulatorias, especialmente el Acta de Modernización de los Servicios Financieros (1999) pero sobre todo el Acta de Modernización de los Mercados a futuros de Materias Primas (2000), una vez desplomada la burbuja financiera alrededor de los activos inmobiliarios en EEUU, un sinfín de actores tales como fondos de inversión libre, fondos de pensión, fondos universitarios, compañías aseguradoras, fondos soberanos y bancos, comenzaron a diversificar sus portafolios a través de inversiones en los mercados de futuros, ${ }^{2}$ concretamente a través de inversiones en fondos de índice de materias primas.

Así, convertidas en una suerte de refugio para la inversión, tras la implosión de los mercados financieros de vivienda, el volumen de operaciones en los mercados de futuros, concretamente en fondos de índice de materias primas, se disparó de manera estrepitosa

\section{Lámina 2:}

Según datos presentados por Masters y White (2008), el tamaño del mercado de futuros de commodities pasó de 91 mil millones de dólares en 2002 a 835.2 miles de millones en 2008. Por su parte, un estudio realizado por Lehman Brothers, justo antes de su quiebra, reveló que el volumen de la especulación de fondos de índice aumentó en un 1,900\% entre 2003 y marzo de 2008. Morgan Stanley afirma que las inversiones en fondos de índices de materias primas se dispararon de 13 mil millones de dólares en 2003 a 260 mil millones en 2008 (Medina, 2011: 55).

Las materias primas que dominan los índices de futuros son las relacionadas con la energía: el petróleo crudo representa el $51.4 \%$ y todos los productos relacionados con el

\footnotetext{
${ }^{2}$ En términos generales los mercados de futuro refieren a transacciones en donde se negocian contratos de futuro, es decir acuerdos de compra o venta de un activo en una fecha futura establecida a un precio determinado. Como explica Delgado Selley, "estas inversiones no tienen rendimiento, la única fuente de retorno es el incremento en el precio de los futuros contratos" (2011:95).
} 
petróleo el 78.2\%. Por su parte, los mayores pesos de las materias primas agrícolas corresponden al maíz, soya y trigo (Wray, 2008: 25). Durante la primera década del siglo XXI, ocho commodities tuvieron incrementos superiores al 500\%, entre ellos el petróleo que alcanzó un incremento de $1312 \%$.

Como explica Delgado Selley, este incremento se deriva de que los precios presentes (spot) se fijan a partir de los precios futuros, es decir:

\section{Lámina 2/2}

La manera en que los precios de los futuros elevan el precio en los mercados spot es a través del "descubrimiento del precio". La producción de commodities es local, mientras que el consumo final está geográficamente disperso: productores e intermediarios desconocen el precio al que se vendería su producción. Sin embargo, los precios en los mercados de futuros están disponibles en tiempo real mostrando la oferta y demanda de esos frutos. Naturalmente, los mercados locales se apoyan en los precios de los mercados de futuros como la fuente básica de información de precios. De modo que los cambios de precios en los futuros se transmiten directamente a los mercados spot (Delgado, 2011:96).

Como señalamos, derivado del carácter petrodependiente de la agricultura industrial, el precio de los alimentos, y de las materias primas agrícolas en general, está directamente relacionado con el precio del crudo. En este sentido, y como se observa en las gráficas 2 y 3 , al comportamiento secular del precio del petróleo ha correspondido un comportamiento casi equivalente en el precio de los alimentos.

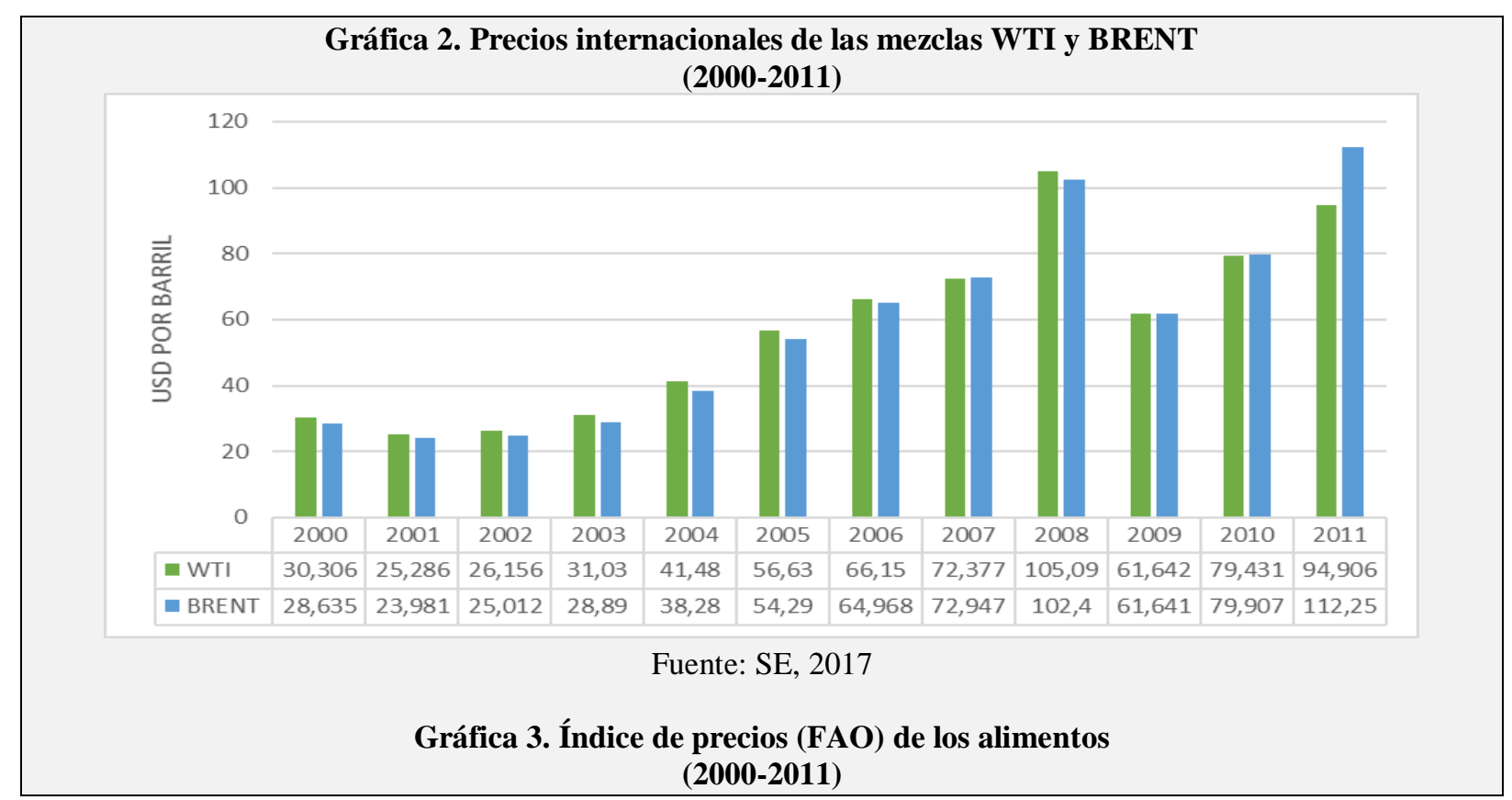




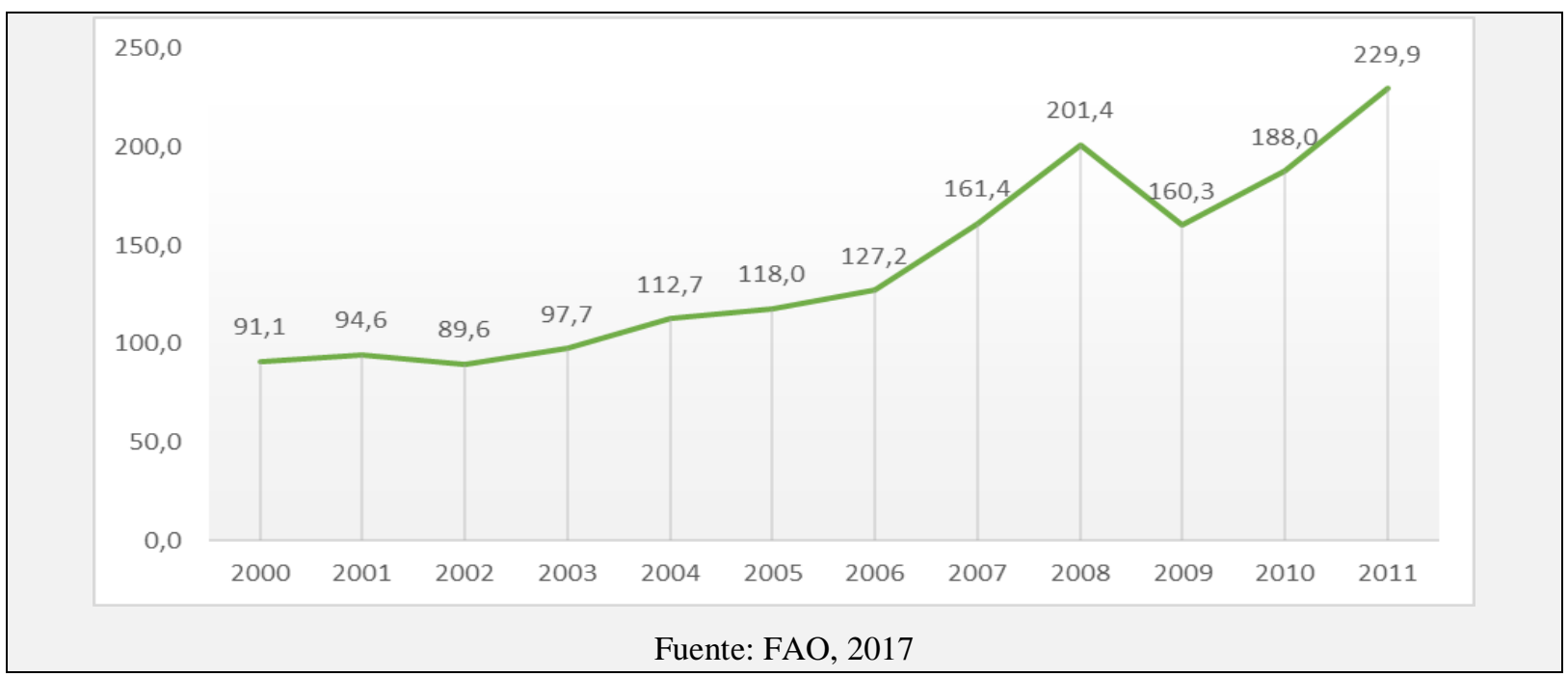

En este sentido, contrario a lo que muchos analistas y especuladores argumentan, el alza del precio de los alimentos, que en 2008 alcanzó cifras récord luego superadas en el 2011, no es el resultado de un desacoplamiento entre la capacidad productiva y la demanda global. Aunque incidida por factores de diversa índole, la razón de fondo del alza del precio de los alimentos y de las materias primas en general, está directamente relacionada con el boom de las actividades financieras en los mercados de futuros de materias primas (commodities).

Ahora bien, a partir de los últimos años, a esta relación consustancial entre el precio del crudo y de los alimentos - precios sometidos a la intensa actividad financiera global - se ha agregado un elemento novedoso que complejiza aún más la correlación de los precios de los alimentos con el ámbito energético: la producción a gran escala de biocombustibles.

\section{LA ENERGÍA SE SIEMBRE}

En el marco de la escasez de los recursos energéticos fósiles en general, y del significativo aumento de la demanda energética, asistimos a un proceso de re-valorización de las fuentes energéticas tanto primarias como secundarias. Así, en paralelo al aseguramiento de las fuentes energéticas fósiles, y que en Latinoamérica avanzan principalmente a través de la apertura al capital privado del sector Downstream; en las últimas décadas ha avanzado la búsqueda de nuevas energías capaces de satisfacer las necesidades energéticas de la industria mundial entre las que destacan los agrocombustibles.

Actualmente existen dos agrocombustibles líquidos de primera generación que ocupan la escena mundial: el bioetanol que se produce principalmente a partir de caña de azúcar y 
maíz, aunque también se obtiene a partir de trigo, betabel, yuca y sorgo; y el biodiesel que se obtiene a partir de aceites o grasas. Ciertas plantas como la soya, la palma africana, la colza, el girasol, el ricino, la canola y el piñón son las que "más eficientemente" producen aceites que pueden ser utilizados directamente como agrocombustibles, o ser procesados para obtener otro más refinado (Montico, 2007).

Aunque la producción de agrocombustibles revela relaciones muy poco eficientes, en los últimos años esta industria ha crecido notablemente.

\section{Lámina 4}

Según datos presentados por el BM, mientras que en el año 2004 el área agrícola estimada mundial con cultivos para la producción de agrocombustibles se calculaba en 21 millones de hectáreas, en el 2008 la cifra alcanzó 36 millones (Llana, 29/03/2007). Por su parte, datos presentados por Lester R. Brown (2011) revelan que entre el año 2000 y 2010 la producción mundial de biodisel pasó de 213 a 5,253 millones de galones, mientras que la producción de fuel etanol pasó de 4,519 a 21,926 millones de galones.

Gráfica 4. Producción mundial de biodiésel y etanol (2000-2010)

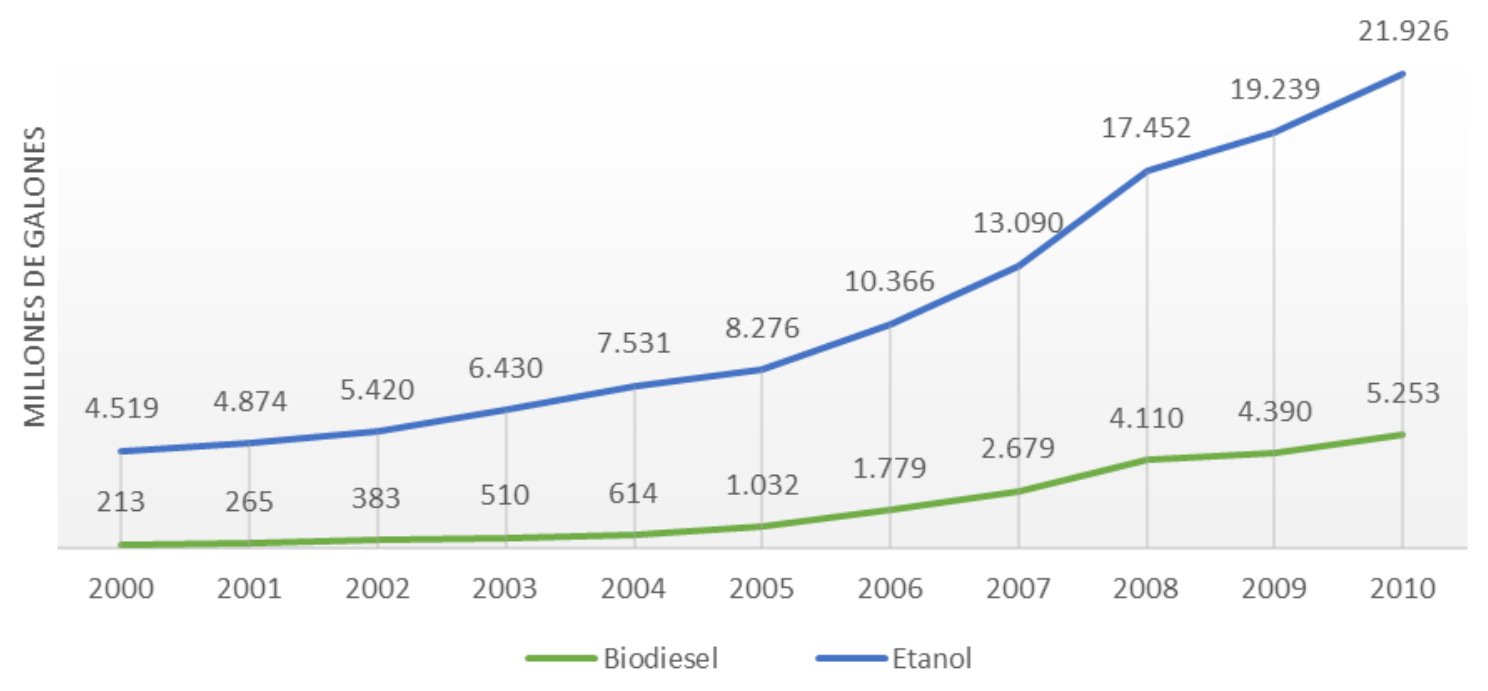

Fuente: Lester R. Brown, 2011

El impulso a la producción de bioenergía -cuyo futuro y expansión depende directamente de la producción agrícola- además de disparar el precio de los commodities agrícolas, está generando un nuevo vínculo entre el mercado energético y el mercado agrícola. 
Como la propia FAO reconoce, el ascenso de los agrocombustibles tiende a convertir a los llamados cultivos energéticos en los que comandan la estructura productiva, ya que son los que crecen más rápido y tienden a ocupar la mayor parte de la superficie sembrada.

Toda vez que los mercados energéticos son mayores que los alimentarios, esta relación apuntala que sea la demanda energética y no la demanda de alimentos, la que fija los precios de los productos agrícolas mismos que quedan vinculados a los precios de la energía (FAO, 2005:22).

\section{Lámina 5:}

Esta relación entre el mercado energético y el mercado agrícola, a partir del cual se configura una nueva ruta de mercantilización de los productos agropecuarios, se observa claramente en el comportamiento que registran los precios de los cereales, oleaginosas y azúcar, todos ellos insumos básicos para la elaboración de biocombustibles.

Gráfica 5. Comportamiento del índice de precios (FAO) de cereales, aceites- grasas y azúcar (2000-2011)

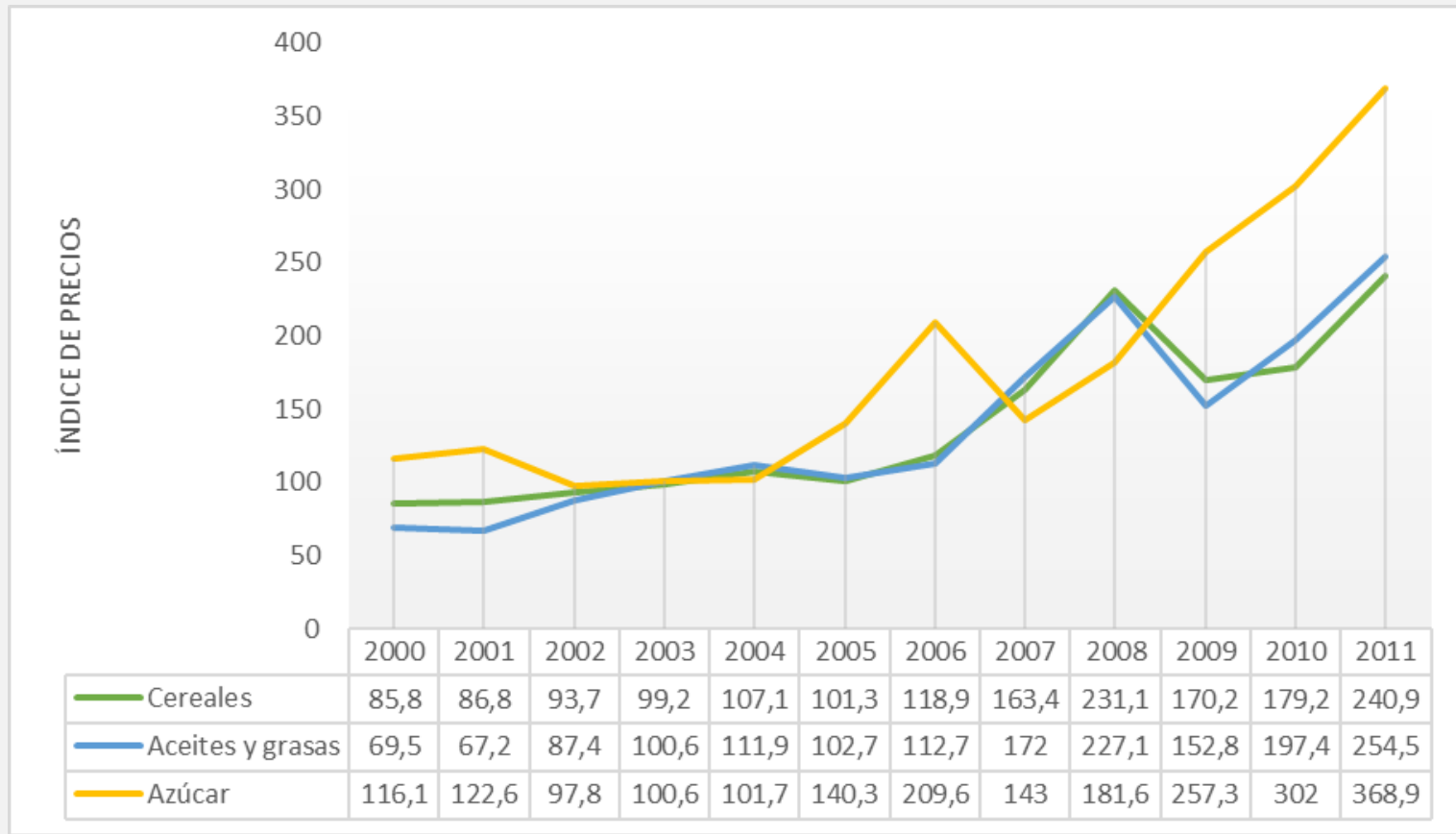

Fuente: FAO, 2014 


\section{ACAPARAMIENTO DE TIERRAS}

\section{Lámina 6:}

En un mundo en el que cerca del $70 \%$ de los países subdesarrollados son importadores netos de alimentos, y en el que el gasto en este rubro supone entre el 50 y el $80 \%$ del gasto total del hogar (Rubio, 2008:48; Sumpsi, 2009: 29), el alza del precio de los alimentos ha traído consecuencias desastrosas.La FAO estima que tan sólo entre 2007 y 2008, 115 millones de personas fueron condenadas al hambre crónica, sumándose a los más de 850 millones que ya se encontraban en esta condición (FAO, 2008).

Ahora bien, sumado a la configuración de una crisis alimentaria de magnitudes históricas que se gesta en el marco de un aumento o sostenimiento de la producción mundial y que, sin embargo, por el incremento en el precio de los alimentos genera desabasto, a partir de la alta rentabilidad del sector agropecuario o en su defecto, de la inestabilidad del precio de los alimentos, la tierra agrocultivable ha sufrido un proceso de revalorización (capitalista), a partir del cual se ha desencadenado un nuevo ciclo mundial de acaparamiento que por su magnitud, se perfila ya como uno de los rasgos que definirán el carácter del nuevo siglo.

\section{Lámina 6:}

Los datos recopilados por la organización Land Matrix Partnership ilustran cabalmente esta situación: en lo que va del siglo XXI, han sido vendidas o arrendadas más de 227 millones de hectáreas (OXFAM, 2011), superficie superior al doble del territorio que ocupa Honduras, tres veces el territorio de Panamá.

Tal acaparamiento, se traduce, inevitablemente, en un intenso proceso de despojo contra las comunidades rurales de América Latina, es decir, los pueblos indígenas y campesinos de la región. Proceso que se refleja ya, de manera evidente, no sólo en el sin número de movimientos sociopolíticos y dignas resistencias que han emergido en Latinoamérica en los últimos años, relacionados con el ámbito rural, sino, en contraparte, con el alarmante comportamiento que registra la población rural a nivel mundial y especialmente en América Latina y el Caribe en donde el porcentaje de población rural pasó de $50.74 \%$ en 1960 a $20.12 \%$ en 2015, lo que representa un decremento de casi 30 puntos porcentuales en tan solo medio siglo. 


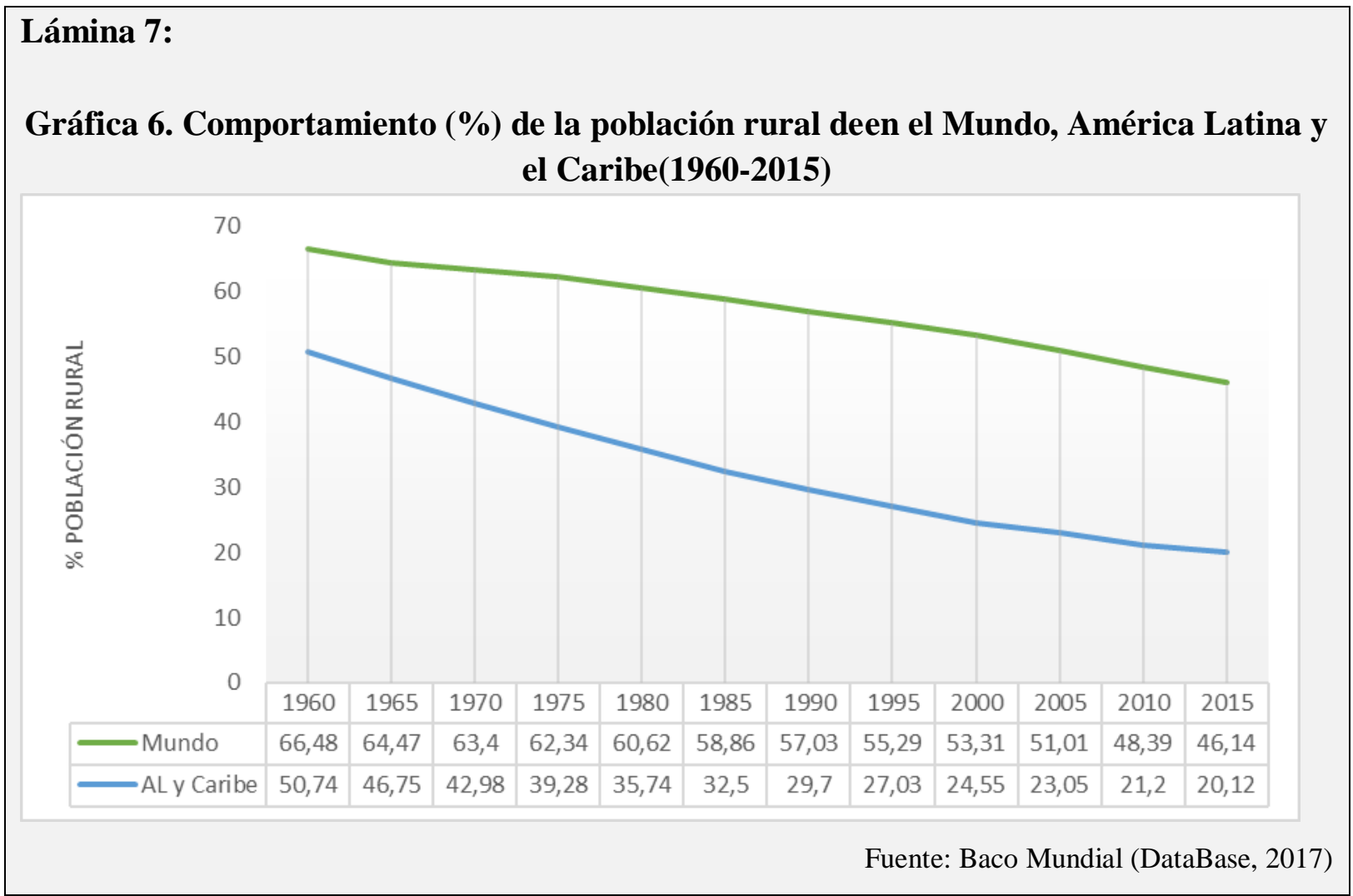

En suma, el boom de la especulación con los alimentos y el impulso a la producción de agrocombustibles han dado lugar a la configuración de un orden agroalimentario mundial de carácter financiero-energético en el que se imponen precios artificiales al alza mediante el mecanismo de especular con el desabasto futuro, merced a la debilidad productiva de los países subdesarrollados.

Por su parte, la orientación de los cereales y oleaginosas para la elaboración de agrocombustibles, mismo que contribuye al sostenimiento al alza de los precios, además de reducir la oferta alimentaria mundial, genera una fuerte presión sobre la orientación de la estructura productiva de los países subdesarrollados para que produzcan bienes alimentarios de exportación dirigidos a atender las necesidades de este nuevo paradigma energético, en detrimento directo de las de por sí mermadas soberanías alimentarias. Es decir, se impulsa un proceso de reconversión productiva en el que los países, principalmente los subdesarrollados, destinan gran parte de su producción agrícola a la siembra de cultivos para la producción de agrocombustibles, lo cual profundiza su ya de por sí mermada soberanía alimentaria. 


\section{CONCLUSIONES}

Bajo el dominio de las agroindustrias multinacionales y del capital financiero especulativo que controla las commodities en las bolsas de valores, en el marco de este nuevo orden agroalimentario, la renta de la tierra no sólo resurge, sino que se genera una renta financiera derivada de la transformación de los alimentos en commodities, con lo cual el conflicto por la tierra cobra un nuevo impulso (Cf. Rubio, 2008: 47-50).

En el marco de esta disputa por la tierra, el acaparamiento se perfila como uno de los rasgos que definirán el carácter del siglo XXI y, por consecuencia, un profundo proceso de despojo dirigido, fundamentalmente, en contra de las comunidades rurales, es decir, los pueblos originarios, indígenas y campesinos de América Latina.

En síntesis, estamos frente a un proceso de reestructuración territorial en donde el capital busca funcionalizar los espacios rurales del planeta, adecuándolos a un nuevo ciclo de acumulación en el que la mayor parte de la población es completamente prescindible. Por eso hoy, la lucha por la tierra es una lucha por el territorio, y en tanto son dos modelos antagónicos: los del capital y los de la humanidad, la lucha por la tierra hoy, en el siglo XXI, es una lucha a muerte por la vida.

\section{BIBLIOGRAFÍA}

BROWN, Lester R., (2011). World On the Edge: How to prevent environmental and economic collapse; [versión electrónica], Earth policy institute, w.w. Norton \& Company, [citado 27/09/12]. Disponible en: http://www.earth-policy.org/books/wote/wote_data.

CÁRDENAS, Carlos Waldimir Gómez; PUELlO-SOCARRÁS, Jose Francisco (2009). El capitalismo contemporáneo y su nueva forma espacial. Un calidoscopio temático para América latina; [versión electrónica], en Transformaciones en el capitalismo latinoamericano. Avances de equipos de investigación. FlSyP, Argentina, [citado 09/09/12]. Disponible en: https://fisyp.org.ar/media/uploads/coy2.pdf.

DELGADO, Gian Carlo (2002). La amenaza biológica. Mitos y falsas promesas de la biotecnología, Plaza y Janes, México.

GILLY, Adolfo; ROUX, Rhina (2008). Capitales, tecnologías y mundos de vida. El despojo de los cuatro elementos; [versión electrónica] en Herramienta debate y crítica marxista, [citado 23/09/12]. Disponible en: http://www.herramienta.com.ar/foro-capitalismo-entrance/capitales-tecnologias-y-mundos-de-la-vida-el-despojo-de-los-cuatro-elemen. 
MASTERS, Michael; WHITE, Adam (2008). The Accidental Hunt Brothers; [versión electrónica], Special

Report, 31 de junio de 2008, [citado 02/03/12]. Disponible en http://www.accidentalhuntbrothers.com/

MONTICO, Sergio (2007). Biocombustibles: cereales y oleaginosos para consumo humano o sustitución de energía fósil; [versión electrónica], Revista de investigaciones de la facultad de ciencias agrárias, n. XII. [citado 25/08/11]. Disponible en: http://www.fcagr.edu.ar.

OXFAM, (2011). Tierra y poder, el creciente escándalo en torno a una nueva oleada de inversiones en tierras; [versión electrónica], 151 informe de oxfam, 22-09-2011, [citado 20/08/13]. Disponible en: https://www.oxfam.org/sites/www.oxfam.org/files/bp151-landpower-rights-acquisitions-220911-es.pdf.

REY, José Maria Medina (2011). Especulación financeira y crisis alimentaria; [versión electrónica], Derecho a la alimentación, Agencia Española de cooperación internacional para el desarrollo. [citado 17/04/13]. Disponible en: http://blogs.elpais.com/files/especulaci\%C3\%B3nfinanciera-y-crisis-alimentaria-1.pdf.

RUBIO, Blanca (2008). La crisis alimentaria y el nuevo orden alimentario financiero energético mundial, Revista mundo siglo XXI, n. 13, CIECAS-IPN, México.

SEOANE, Jose (2012). Neoliberalismo y ofensiva extractivista. Actualidad de la acumulación por despojo, desafíos de Nuestra América; [versión electrónica], Theomai 26, segundo semestre de 2012, Argentina. [citado 17/09/14]. Disponible en: http://www.redalyc.org/articulo.oa?id=12426097006.

WRAY, L. Randall (2008). The commodities market bubble. Money manager capitalism and the financialization of commodities; [versión electrónica], en the levy economics institute of bard college en public policy brief, n. 96, [citado 06/03/12]. Disponible en: http://www.levyinstitute.org/pubs/ppb_96.pdf. 